\title{
Langer mesomelic dysplasia
}

INSERM

\section{Source}

INSERM. (1999). Orphanet: an online rare disease and orphan drug data base. Langer mesomelic dysplasia. ORPHA:2632

Langer mesomelic dysplasia (LMD) is characterized by severe disproportionate short stature with mesomelic and rhizomelic shortening of the upper and lower limbs. 